\title{
8-Hydroxy-2-Deoxyguanosine Levels and Cardiovascular Disease: A Systematic Review and Meta-Analysis of the Literature
}

\author{
Alessandro Di Minno, Linda Turnu, Benedetta Porro, Isabella Squellerio, Viviana Cavalca, ${ }^{1,2}$ \\ Elena Tremoli, ${ }^{1,2}$ and Matteo Nicola Dario Di Minno ${ }^{1,3}$
}

\begin{abstract}
Significance: 8-Hydroxy-2-deoxyguanosine $(8-\mathrm{OHdG})$ is generated after the repair of ROS-mediated DNA damages and, thus, is one of the most widely recognized biomarkers of oxidative damage of DNA because guanosine is the most oxidized among the DNA nucleobases. In several pathological conditions, high urinary levels of oxidized DNA-derived metabolites have been reported (e.g., cancer, atherosclerosis, hypertension, and diabetes). Recent Advances: Even if published studies have shown that DNA damage is significantly associated with the development of atherosclerosis, the exact role of this damage in the onset and progression of this pathology is not fully understood, and the association of oxidative damage to DNA with cardiovascular disease (CVD) still needs to be more extensively investigated. We performed a meta-analysis of the literature to investigate the association among 8-OHdG levels and CVD. Critical Issues: Fourteen studies (810 CVD patients and 1106 controls) were included in the analysis. We found that CVD patients showed higher 8-OHdG levels than controls (SMD: $1.04,95 \% \mathrm{CI}: 0.61,1.47, p<0.001, \mathrm{I}^{2}=94 \%, p<0.001$ ). The difference was confirmed both in studies in which 8-OHdG levels were assessed in urine (MD: 4.43, 95\%CI: $1.71,7.15, p=0.001$ ) and in blood samples (MD: 1.42, 95\%CI: 0.64, 2.21, $p=0.0004$ ). Meta-regression models showed that age, hypertension, and male gender significantly impacted on the difference in 8-OHdG levels among CVD patients and controls. Future Directions: 8-OHdG levels are higher in patients with CVD than in controls. However, larger prospective studies are needed to test 8-OHdG as a predictor of CVD. Antioxid. Redox Signal. 24, 548-555.
\end{abstract}

\section{Introduction}

T HE OCCURRENCE OF CARDIOVASCULAR DISEASE (CVD) is multifactorial and major risk factors are type 2 diabetes, hypertension, smoking, overweight, dyslipidemia (45). In this context, the generation of reactive oxygen species (ROS), which is important in both normal physiology and in the pathogenesis of many diseases, seems to play a relevant role also in CVD development (5). In physiological conditions, ROS are scavenged by the antioxidant system, but when their concentration is too high, an oxidative damage to proteins, lipids, and DNA occurs (39). DNA damages are usually repaired by a specific system and the oxidized products are excreted in urine (38) without further metabolism. Increased urinary levels of the oxidized metabolites were associated with an increased risk of several pathological conditions (8). One of the most widely studied metabolite is 8-hydroxy-2deoxyguanosine (8-OHdG), which is considered as a biomarker of oxidative damage of DNA $(4,18)$ because guanosine is the most oxidized among the DNA nucleobases. High levels of 8-OHdG have been found in fragments of aorta from patients with severe atherosclerotic lesions. In addition, 8-OHdG levels

\footnotetext{
${ }^{1}$ Centro Cardiologico Monzino, IRCCS, Milan, Italy.

${ }^{2}$ Dipartimento di Scienze Cliniche e di Comunità, Università degli Studi di Milano, Milan, Italy.

${ }^{3}$ Department of Advanced Biomedical Sciences, Division of Cardiology, Federico II University, Naples, Italy.
}

(C) Alessandro Di Minno et al. 2016; Published by Mary Ann Liebert, Inc. This Open Access article is distributed under the terms of the Creative Commons Attribution Noncommercial License (http://creativecommons.org/licenses/by-nc/4.0/) which permits any noncommercial use, distribution, and reproduction in any medium, provided the original author(s) and the source are credited. 
have been correlated with the number of vessels involved by the atherosclerotic process $(29,46)$. The relationship between 8-OHdG and atherogenic risk factors has been extensively studied (10). For example, 8-OHdG concentrations were higher in patients with diabetes (36) and hypertension (33). Even if published studies have shown that DNA damage is significantly associated with the development of atherosclerosis $(1,34)$, the exact role of this damage in the onset and progression of this pathology is not fully understood and the association of oxidative damage to DNA with CVD still needs to be more extensively investigated. For this reason, we performed a systematic review and meta-analysis of literature to investigate the association among $8-\mathrm{OHdG}$ levels and CVD.

\section{Methods}

A protocol for this review was prospectively developed, detailing the specific objectives, the criteria for study selection, the approach to assess study quality, the outcomes, and the statistical methods.

\section{Search strategy}

To identify all available studies, a detailed search pertaining to 8-OHdG levels and CVD was conducted according to PRISMA (Preferred Reporting Items for Systematic reviews and Meta-Analyses) guidelines (27). A systematic search was performed in the electronic databases (PubMed, Web of Science, Scopus, EMBASE), using the following search terms in all possible combinations: 8-hydroxy-2-deoxyguanosine, 8hydroxy-2-deoxy guanosine, 8-OHdG OR 8OHdG, 8-OH-dG, 8-OHG, 8-oxo-G, 8-oxo-dG, 8-hydroxydeoxyguanosine, 8-oxoguanine, 8-hydroxy-2-deoxyguanosine OR 8-hydroxyguanine, 8-hydroxyguanosine, 8-oxo-2-deoxyguanosine, 8-oxo-7,8dihydro-2-deoxyguanosine, coronary artery disease, atherosclerosis, ischaemic heart disease, stroke, myocardial infarction, cardiovascular disease, coronary artery disease. The last search was performed on November 11, 2015. The search strategy was developed without any language or publication year restriction.

In addition, the reference lists of all retrieved articles were manually reviewed. In case of missing data, study authors were contacted by e-mail to try to retrieve original data. Two independent authors (A.D.M. and M.N.D.D.M) analyzed each article and performed the data extraction independently. In case of disagreement, a third investigator was consulted (L.T.). Discrepancies were resolved by consensus. Selection results showed a high inter-reader agreement $(\kappa=0.96)$ and have been reported according to PRISMA flowchart (Supplementary Fig. S1; Supplementary Data are available online at www.liebertpub.com/ars).

\section{Data extraction and quality assessment}

According to the prespecified protocol, all studies evaluating 8-OHdG levels in CVD patients were included. Case reports, reviews, and animal studies were excluded. To be included in the analysis, a study had to provide levels of 8OHdG in CVD patients (coronary artery disease [CAD], stroke, peripheral artery disease, and carotid atherosclerosis) and controls. To allow for a pooled analysis of data, studies dosing 8-OHdG levels on samples different from urine or blood (i.e., histological samples), lacking a control group, including a study population with a clinical condition other than CAD, stroke, peripheral artery disease, and carotid atherosclerosis, were excluded from the analysis.

In each study, data regarding sample size, major clinical and demographic variables of patients and controls, and type of 8-OHdG measurement (enzyme-linked immunosorbent assay [ELISA] or mass spectrometry [MS]) were extracted. Formal quality score adjudication was not used since previous investigations failed to demonstrate its usefulness (17).

\section{Statistical analyses and risk of bias assessment}

Statistical analysis was carried out using the Review Manager software (Version 5.2; The Cochrane Collaboration, Copenhagen, Denmark). Because of the heterogeneity in the methods used for measuring $8-\mathrm{OHdG}$ in included studies, differences among cases and controls were expressed as standard mean difference (SMD) with pertinent $95 \%$ confidence interval $(95 \% \mathrm{CI})$. According to widely accepted guidelines, SMD is considered small if ranging from 0.2 to 0.5 , medium if $0.5-0.8$, and large if $>0.8$. (9) When separately assessing studies in which $8-\mathrm{OHdG}$ levels were evaluated in urine and blood, differences among cases and controls were expressed as mean difference (MD) with $95 \%$ CI. The overall effect was tested using $\mathrm{Z}$ scores and significance was set at $p<0.05$. Statistical heterogeneity between studies was assessed with chi-square Cochran's Q test and with $I^{2}$ statistic, which measures the inconsistency across study results and describes the proportion of total variation in study estimates that is due to heterogeneity rather than sampling error. In detail, $I^{2}$ values of $0 \%$ indicate no heterogeneity, $25 \%$ low, 25-50\% moderate, and 50\% high heterogeneity (12). Publication bias was assessed by the Egger's test and represented graphically by funnel plots of the standard difference in means versus the standard error. Visual inspection of funnel plot asymmetry was performed to address for possible smallstudy effect, and Egger's test was used to assess publication bias, over and above any subjective evaluation. A value of $p<0.10$ was considered statistically significant (41). In case of a significant publication bias, Duval and Tweedie's trim and fill method was used to allow for the estimation of an adjusted effect size (6). To be as conservative as possible, the random-effect method was used for all analyses to take into account the variability among included studies.

\section{Sensitivity analyses}

In the frame of a sensitivity analysis, results have been stratified according to the type of vascular disease (CAD, stroke, peripheral artery disease, and carotid atherosclerosis) and study design (prospective or retrospective). Given the potential influence of type of $8-\mathrm{OHdG}$ measurement on the overall effect size, we planned to perform separate analyses for studies using ELISA and those using MS. Moreover, we separately analyzed studies dosing $8-\mathrm{OHdG}$ on urine and studies dosing 8-OHdG on blood samples.

\section{Metaregression analyses}

We hypothesized that differences among included studies may be affected by demographic variables (mean age, male gender) and coexistence of traditional cardiovascular risk factors (hypertension, smoking habit, diabetes mellitus, obesity, 


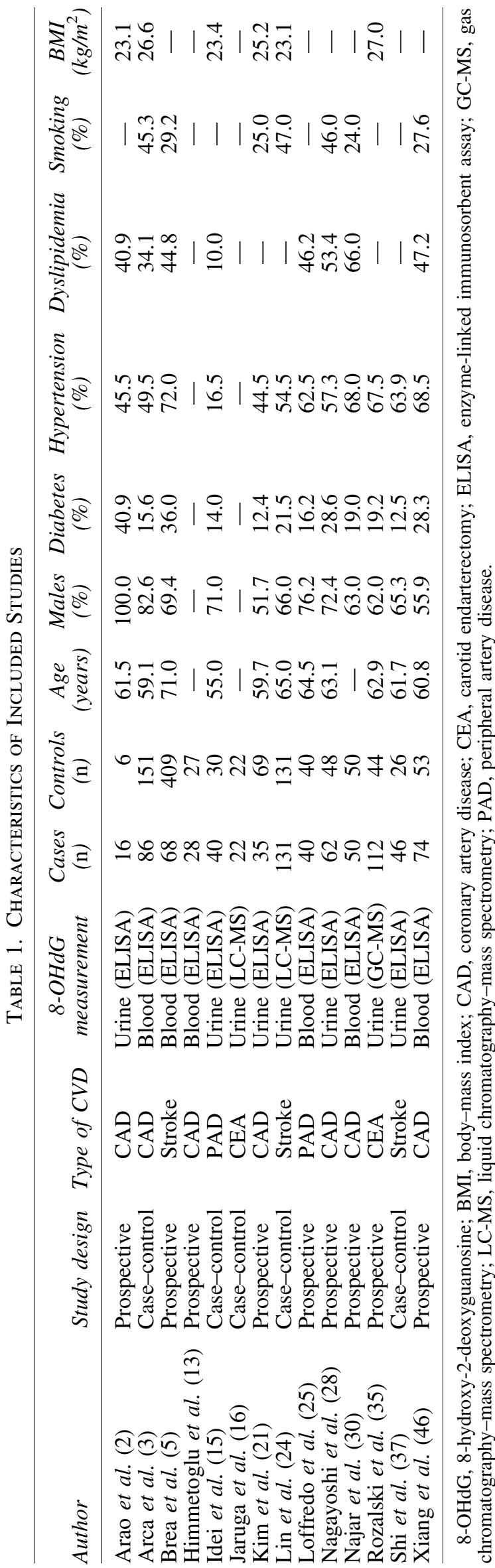

hyperlipidemia). To assess the possible effect of such variables in explaining different results observed across studies, we planned to perform metaregression analyses after implementing a regression model with $8-\mathrm{OHdG}$ levels as dependent variables $(y)$ and the abovementioned covariates as independent variables $(x)$. This analysis was performed with Comprehensive Meta-analysis (Version 2; Biostat, Englewood, NJ).

\section{Results}

After excluding duplicate results, the search retrieved 877 articles. Of these studies, 847 were excluded because they were off the topic after scanning the title and/or the abstract and because they were reviews/comments/case reports or they lacked data of interest. A total of 16 studies were excluded after full-length article evaluation (Supplementary Table S1).

Thus, 14 studies $(2,3,5,13,15,16,21,24,25,28,30,35$, 37, 46) on 810 CVD patients and 1106 controls were included in the final analysis (Supplementary Fig. S1). In detail, three studies on stroke (245 cases and 566 controls) $(5,24,37)$, seven on CAD (351 cases and 404 controls) $(2,3,13,21,28$, $30,46)$, two on patients with carotid atherosclerosis undergoing carotid endarterectomy (134 cases and 66 controls) $(16,35)$, and two on peripheral artery disease (80 cases and 70 controls) $(15,25)$ were included.

\section{Study characteristics}

Major characteristics of included studies are shown in Table 1 . A total of five studies $(3,15,16,24,37)$ were casecontrol studies and nine $(2,5,13,21,25,28,30,35,46)$ had a prospective design. In 11 studies, an ELISA was used to perform 8-OHdG level assessment $(2,3,5,13,15,21,25,28$, $30,37,46)$, and in 3 studies, liquid or gas chromatography MS $(16,24,35)$. As to the type of sample, in eight studies (464 CVD patients and 376 controls), 8-OHdG levels were assessed in urinary samples $(2,15,16,21,24,28,35,37)$, and in six studies (346 CVD patients and 730 controls), blood samples were used $(3,5,13,25,30,46)$.

The number of patients varied from 16 to 131, the mean age from 55 to 71 years, and the prevalence of male gender from $51.7 \%$ to $100 \%$. The presence of hypertension was reported by $16.5 \%-72.0 \%$ of patients, smoking habit by $24 \%-$ $47 \%$, diabetes mellitus by $12.4 \%-40.9 \%$, and dyslipidemia by $10 \%-53.4 \%$. Mean body-mass index (BMI) varied from $23.1 \mathrm{~kg} / \mathrm{m}^{2}$ to $27.0 \mathrm{~kg} / \mathrm{m}^{2}$.

In the 14 studies, we found that 810 CVD patients showed significantly higher 8-OHdG levels than the 1106 controls (SMD: 1.04, 95\% CI: 0.61-1.47, $p<0.00001, I^{2}=94 \%$, $p<0.00001)$. As shown in Figure 1, the difference was consistently confirmed both in studies in which 8 -OHdG levels were assessed in urine (MD: $4.43 \mathrm{ng} / \mathrm{mg}$ creatinine, $95 \% \mathrm{CI}$ : $1.71-7.15, p=0.001$ ) and in studies using blood samples (MD: $1.42 \mathrm{ng} / \mathrm{ml}, 95 \% \mathrm{CI}: 0.64-2.21, p=0.0004)$. Heterogeneity among studies was statistically significant in all cases $\left(I^{2}=98 \%, p<0.00001\right.$ and $I^{2}=94 \%, p<0.00001$, respectively) and no reduction in the overall heterogeneity was found after excluding one study at a time.

\section{Sensitivity analysis}

As shown in Table 2, similar results were obtained when stratifying analysis according to the type of vascular disease 
FIG. 1. 8-OHdG levels in CVD patients and controls. 8-OHdG, 8-hydroxy-2deoxyguanosine; CVD, cardiovascular disease.

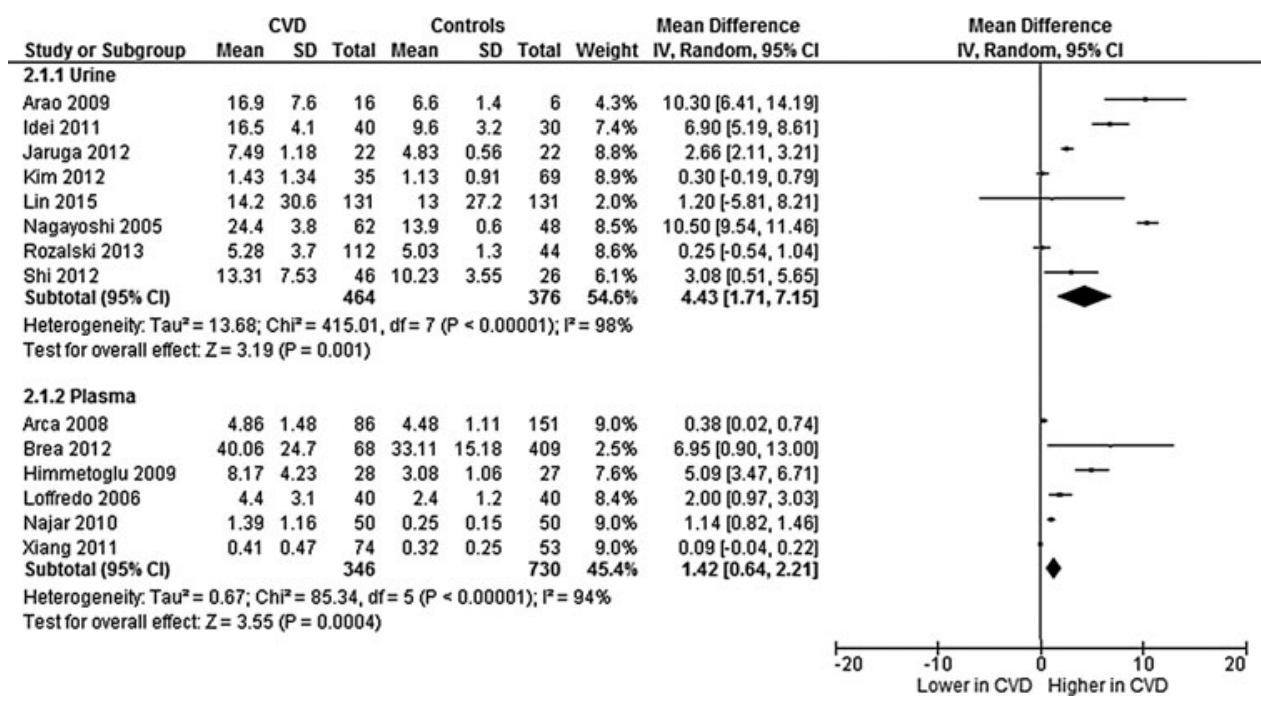

(CAD, stroke, peripheral artery disease, and carotid atherosclerosis), different $8-\mathrm{OHdG}$ measurement techniques, and study design.

\section{Metaregression analyses}

Metaregression models showed that an increasing mean age and an increasing prevalence of hypertension in the study population were associated with a lower difference in 8-OHdG levels among CVD patients and controls (Fig. 2). In contrast, a higher difference in 8-OHdG levels among CVD patients and controls was found in the presence of a higher prevalence of male gender (Fig. 2). All the other clinical and demographic variables tested did not influence the association between 8-OHdG and CVD (Supplementary Fig. S2).

\section{Publication bias}

Because it is recognized that publication bias can affect the results of meta-analyses, we attempted to assess this potential bias using funnel plot analysis. Funnel plots of effect size versus standard error for studies evaluating levels of 8-OHdG in CVD patients and controls were rather asymmetrical, and the Egger test confirmed the presence of a significant publication bias (Egger $=0.001$, Supplementary Fig. S3). However, the adjusted analysis by means of Duval and Tweedie's trim and fill method confirmed differences in 8-OHdG levels among CVD patients and controls with an SMD of 1.25 (95\% CI: 0.72-1.78, Supplementary Fig. 3).

\section{Discussion}

This is the first meta-analysis, to our best knowledge, showing that $8-\mathrm{OHdG}$ levels are higher in patients with CVD than in controls. Interestingly, these data were confirmed when separately evaluating studies, including CAD patients, and those on patients with other types of atherosclerotic processes (stroke, peripheral artery disease, and carotid atherosclerosis).

Further relevant information was derived from the metaregression analysis, showing that the association among

Table 2. Subgroup Analysis: Stratification of the Analysis According to Different Vascular Diseases (Coronary Artery Disease, Stroke, Peripheral Artery Disease, and Carotid Atherosclerosis) (A), Different Techniques (B), and Samples (C) Used for 8-OHdG Measurement

\begin{tabular}{|c|c|c|c|c|}
\hline & $\begin{array}{l}\text { No. of } \\
\text { studies }\end{array}$ & $\begin{array}{l}\text { No. of } \\
\text { patients }\end{array}$ & Effect size & $\begin{array}{l}\text { Test for subgroup } \\
\text { differences }\end{array}$ \\
\hline \multicolumn{5}{|c|}{ (A) Different type of cardiovascular disease } \\
\hline Coronary artery disease & 7 & $\begin{array}{l}351 \text { Cases } \\
404 \text { Controls }\end{array}$ & $\begin{array}{l}\text { SMD: } 1.24 ; 95 \% \text { CI: } 0.47 \text { to } 2.01 \\
\quad p<0.002, I^{2}: 95 \%, p<0.00001\end{array}$ & \multirow[t]{2}{*}{$\chi^{2}: 0.75, p=0.39$} \\
\hline Noncoronary artery diseases ${ }^{\mathrm{a}}$ & 7 & $\begin{array}{l}459 \text { Cases } \\
702 \text { Controls }\end{array}$ & $\begin{array}{c}\text { SMD: } 0.83 ; 95 \% \text { CI: } 0.33 \text { to } 1.34 \\
p=0.001, I^{2}: 91 \%, p \leq 0.0001\end{array}$ & \\
\hline \multicolumn{5}{|c|}{ (B) Different techniques for $8-\mathrm{OHdG}$ measurement } \\
\hline ELISA & 11 & $\begin{array}{l}545 \text { Cases } \\
909 \text { Controls }\end{array}$ & $\begin{array}{c}\text { SMD: } 1.09 ; 95 \% \text { CI: } 0.60 \text { to } 1.58 \\
\quad p<0.0001, I^{2}: 93 \%, p<0.00001\end{array}$ & \multirow[t]{2}{*}{$\chi^{2}: 0.16, p=0.69$} \\
\hline GC/LC-MS & 3 & $\begin{array}{l}265 \text { Cases } \\
197 \text { Controls }\end{array}$ & $\begin{array}{l}\text { SMD: } 0.86 ; 95 \% \text { CI: }-0.15 \text { to } 1.87 \\
\quad p=0.09, I^{2}: 95 \%, p<0.00001\end{array}$ & \\
\hline \multicolumn{5}{|l|}{ (C) Different study design } \\
\hline Case-control studies & 5 & $\begin{array}{l}325 \text { Cases } \\
360 \text { Controls }\end{array}$ & $\begin{array}{c}\text { SMD: } 1.00 ; 95 \% \text { CI: }-0.30 \text { to } 1.71 \\
\quad p=0.005, I^{2}: 94 \%, p<0.00001\end{array}$ & \multirow[t]{2}{*}{$\chi^{2}: 0.02, p=0.90$} \\
\hline Prospective studies & 9 & $\begin{array}{l}485 \text { Cases } \\
746 \text { Controls }\end{array}$ & $\begin{array}{l}\text { SMD: } 1.06 ; 95 \% \text { CI: } 0.48 \text { to } 1.65 \\
\quad p=0.0004, I^{2}: 94 \%, p<0.00001\end{array}$ & \\
\hline
\end{tabular}

${ }^{a}$ Including three studies on stroke, two on carotid atherosclerosis, and two on peripheral artery disease.

95\% CI, 95\% confidence interval; SMD, standard mean difference. 

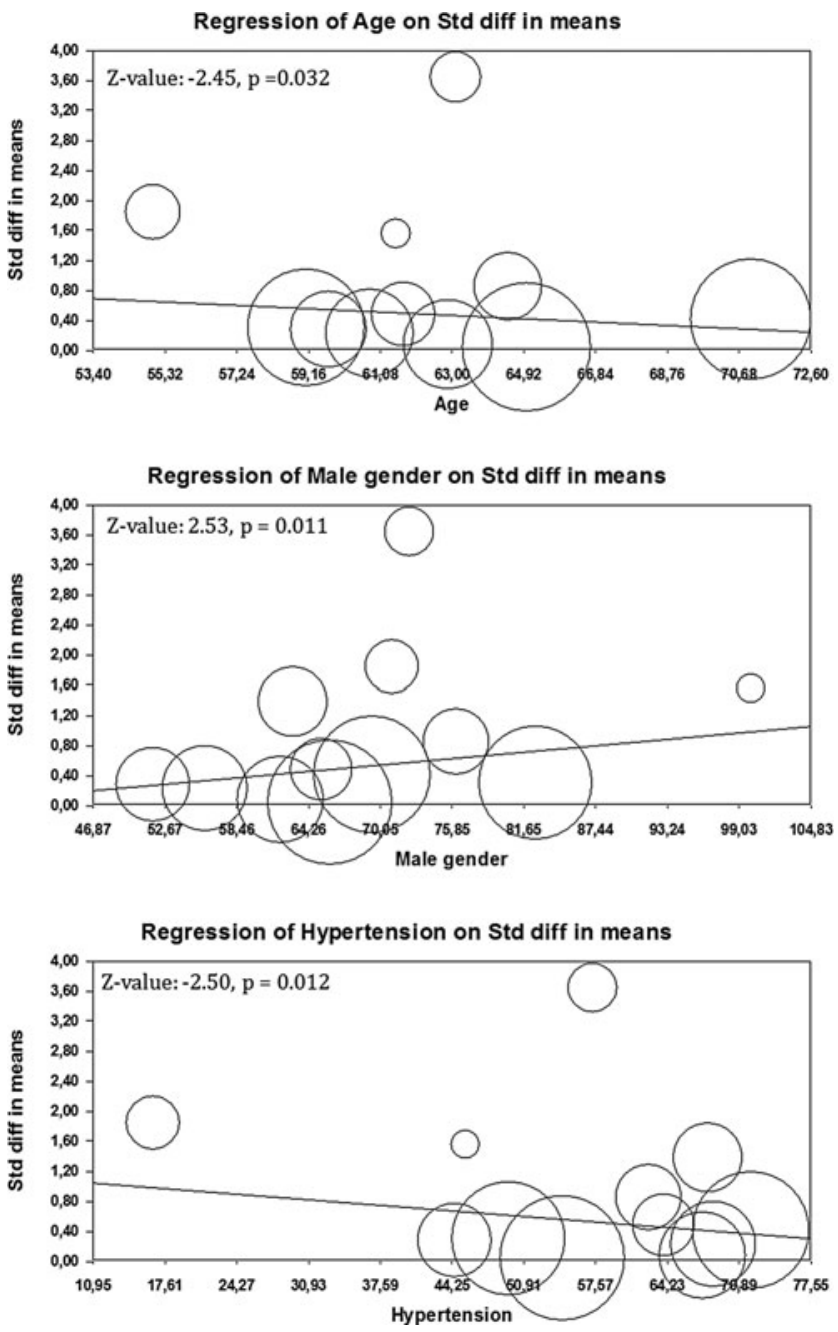

FIG. 2. Metaregression analysis. Clinical and demographic characteristics impacting the effect size.

8-OHdG levels and CVD is largely independent of diabetes, hyperlipidemia, BMI, and smoking habit. In contrast, an increasing age significantly impacted on the effect size, with the association among 8-OHdG levels and CVD being stronger in younger subjects. Thus, $8-\mathrm{OHdG}$ might represent a better marker of CVD in a young population. This might be consequent to the reduction in DNA turnover associated with aging (11). Similarly, an increasing prevalence of hypertension in the study population was associated with a lower difference in 8-OHdG levels among CVD patients and controls. This might be explained by some evidence suggesting that $8-\mathrm{OHdG}$ levels are significantly higher in hypertensive subjects than normotensive controls (31). These data are in line with results of the study by Mendes et al. (26), showing that patients with cardiovascular risk factors have threefold higher levels of urinary 8-OHdG than controls.

We also found that gender might impact on the effect size of our meta-analysis. Indeed, the difference in 8-OHdG levels among CVD patients and controls was lower in female gender than in males. This finding is supported by some previously published data (23) suggesting that $8-\mathrm{OHdG}$ levels are higher in females. In addition, the inclusion of postmenopausal women, in which the antioxidant effect of estrogens has been lost, can partially explain this finding (32, 42). A further potential explanation of gender differences in 8-OHdG urinary levels can be represented by the higher muscle mass of male subjects, thus leading to higher creatinine levels $(7,43)$.

Several cardiovascular risk factors, such as hypercholesterolemia, diabetes, hypertension, and atherosclerosis, are associated with an increased oxidative stress (20), which is the consequence of an imbalance between the generation of ROS and the activity of antioxidant defense system, due to endogenous or exogenous environmental factors and can induce oxidation of biological macromolecules such as proteins, lipids, and DNA (39).

Because of the high instability of ROS, the degree of oxidative stress can be better evaluated by the assessment of stable metabolites of oxidative reactions. $8-\mathrm{OHdG}$ is a product of oxidative DNA damage and is widely recognized as a biomarker of the in vivo total systemic oxidative stress $(38,40,47)$.

Oxidative stress is implicated in the pathogenesis of several diseases such as cancer, ischemia/reperfusion injury, diabetes, neurodegenerative and immunoinflammatory diseases, and atherosclerosis (44). In particular, the increase in 8-OHdG concentrations in CVD patients, secondary to ROSmediated DNA damage, could mirror severity of the atherosclerotic process (22).

However, available studies on this issue are heterogeneous, providing contrasting results on the association among 8-OHdG levels and CVD. This meta-analysis, by pooling together 14 studies enrolling 810 CVD patients and 1106 controls, has allowed to further address this issue. Moreover, two studies by Ho et al. (14) and Kaya et al. (19), not included in the present meta-analysis because they performed the evaluation of DNA damage in DNA extracted from white blood cell and expressed the ratio between $8-\mathrm{OHdG}$ and $10^{6}$ dG (Supplementary Table S1), widely confirmed our results. When pooling together data from these two studies, we found higher levels of $8-\mathrm{OHdG}$ in the $154 \mathrm{CAD}$ patients than in the 97 controls (SMD: 1.79, 95\% CI: 1.49-2.09, $\left.p<0.001, I^{2}: 0 \%, p=0.45\right)$. Thus, data obtained on this biological matrix confirm and strengthen findings reported on urine and blood samples.

In another study (29), also not included, patients with heart failure were divided in two groups on the basis of CAD presence. This study showed no statistical difference between patients with or without CAD. When patients were divided in four subgroups on the basis of the New York Heart Association functional classification, the difference, in terms of $8-\mathrm{OHdG}$, between patients with a more severe CAD and controls became statistically significant.

Moreover, confirming and extending the association between 8-OHdG levels and CAD, two studies showed a progressive reduction of $8-\mathrm{OHdG}$ levels in CAD patients after reperfusion $(13,28)$.

Our study has some potential limitations. First, studies included in this meta-analysis have different inclusion and exclusion criteria and most of patients included in the analysis had concomitant cardiovascular risk factors and different types of CVDs. Since this meta-analysis is performed on aggregate data and some missing information is present in each study, the metaregression approach allowed for the adjustment for some (but not all) potential confounders. 
Thus, although results of metaregression analyses were able to refine analyses by assessing the influence of most clinical and demographic variables on the observed results, caution is necessary in overall result interpretation. However, although the absence of a multivariate analysis hampers the exclusion of a confounding effect due to other covariates potentially affecting the association among 8-OHdG levels and CVD, one of the included studies (46) showed that after adjusting for male gender, smoking, hypertension, hyperlipidemia, diabetes mellitus, and age, 8 -OHdG levels were independently associated with the presence of CAD. In detail, a $0.1 \mathrm{ng} / \mathrm{ml}$ increase in 8-OHdG concentration was associated with an odds ratio of $1.318(95 \% \mathrm{CI}: 1.032-1.682, p=0.027)$ for the presence of CAD (46).

The presence of significant heterogeneity among the studies needs to be discussed. An important source of heterogeneity could be due to the variability in laboratory methods used to evaluate $8-\mathrm{OHdG}$. A validated standard technique has not yet been identified and, as shown in Table 1 , different techniques on different samples have been used in the included studies. In our meta-analysis, we have tried to address this issue by splitting analyses according to different techniques used for 8-OHdG measurement (ELISA or MS). While data were entirely confirmed in studies using the ELISA method, only a trend not achieving statistical significance was found in the studies in which MS techniques were used. However, the lack of a significant association in this latter group of studies could be partly explained by the relatively low number of studies $(n=3)$ using MS for the dosage of 8-OHdG levels. In addition, differences in $8-\mathrm{OHdG}$ levels have been consistently confirmed both in studies performed on urine samples and in studies on blood samples. Although it was not possible to conclusively ascertain sources of heterogeneity, all results were confirmed after adjusting for the presence of publication bias.

In conclusion, 8-OHdG is significantly associated with both $\mathrm{CAD}$ and other types of atherosclerotic processes (stroke, peripheral artery disease, and carotid atherosclerosis). The standardization of a laboratory technique for 8OHdG assessment, however, is still needed to allow for large prospective studies that are able to test $8-\mathrm{OHdG}$ as a predictor of CVD.

\section{References}

1. Andreassi MG, Botto N, Cocci F, Battaglia D, Antonioli E, Masetti S, Manfredi S, Colombo MG, Biagini A, and Clerico A. Methylenetetrahydrofolate reductase gene C677T polymorphism, homocysteine, vitamin B12, and DNA damage in coronary artery disease. Hum Genet 112: 171-177, 2003.

2. Arao K, Yasu T, Umemoto T, Jinbo S, Ikeda N, Ueda S, Kawakami M, and Momomura S. Effects of pitavastatin on fasting and postprandial endothelial function and blood rheology in patients with stable coronary artery disease. Circ J 73: 1523-1530, 2009.

3. Arca M, Conti B, Montali A, Pignatelli P, Campagna F, Barilla F, Tanzilli G, Verna R, Vestri A, Gaudio C, and Violi F. C242T polymorphism of NADPH oxidase p22phox and recurrence of cardiovascular events in coronary artery disease. Arterioscler Thromb Vasc Biol 28: 752-757, 2008.
4. Beckman KB and Ames BN. Oxidative decay of DNA. $J$ Biol Chem 272: 19633-19636, 1997.

5. Brea D, Roquer J, Serena J, Segura T, and Castillo J. Oxidative stress markers are associated to vascular recurrence in non-cardioembolic stroke patients non-treated with statins. BMC Neurol 12: 65, 2012.

6. Duval S and Tweedie R. Trim and fill: a simple funnel-plotbased method of testing and adjusting for publication bias in meta-analysis. Biometrics 56: 455-463, 2000.

7. Edwards KD and Whyte HM. Creatinine excretion and body composition. Clin Sci 18: 361-366, 1959.

8. Evans MD, Dizdaroglu M, and Cooke MS. Oxidative DNA damage and disease: induction, repair and significance. Mutat Res 567: 1-61, 2004.

9. Faraone SV. Interpreting estimates of treatment effects: implications for managed care. P T 33: 700-711, 2008.

10. Gackowski D, Kruszewski M, Jawien A, Ciecierski M, and Olinski R. Further evidence that oxidative stress may be a risk factor responsible for the development of atherosclerosis. Free Radic Biol Med 31: 542-547, 2001.

11. Gorbunova V, Seluanov A, Mao Z, and Hine C. Changes in DNA repair during aging. Nucleic Acids Res 35: 74667474, 2007.

12. Higgins JP, Thompson SG, Deeks JJ, and Altman DG. Measuring inconsistency in meta-analyses. BMJ 327: 557560, 2003.

13. Himmetoglu S, Dincer Y, Bozcali E, Ali Vural V, and Akcay T. Oxidative DNA damage and antioxidant defense after reperfusion in acute myocardial infarction. J Investig Med 57: 595-599, 2009.

14. Ho HY, Cheng ML, Chen CM, Gu PW, Wang YL, Li JM, and Chiu DT. Oxidative damage markers and antioxidants in patients with acute myocardial infarction and their clinical significance. Biofactors 34: 135-145, 2008.

15. Idei N, Nishioka K, Soga J, Hidaka T, Hata T, Fujii Y, Fujimura N, Maruhashi T, Mikami S, Teragawa H, Kihara Y, Noma K, Chayama K, and Higashi Y. Vascular function and circulating progenitor cells in thromboangitis obliterans (Buerger's disease) and atherosclerosis obliterans. Hypertension 57: 70-78, 2011.

16. Jaruga P, Rozalski R, Jawien A, Migdalski A, Olinski R, and Dizdaroglu M. DNA damage products $\left(5^{\prime} \mathrm{R}\right)$ - and $\left(5^{\prime} \mathrm{S}\right)$ $8,5^{\prime}$-cyclo-2'-deoxyadenosines as potential biomarkers in human urine for atherosclerosis. Biochemistry 51: 18221824, 2012.

17. Juni $P$, Witschi A, Bloch R, and Egger M. The hazards of scoring the quality of clinical trials for meta-analysis. JAMA 282: 1054-1060, 1999.

18. Kasai H. Analysis of a form of oxidative DNA damage, 8-hydroxy-2'-deoxyguanosine, as a marker of cellular oxidative stress during carcinogenesis. Mutat Res 387: 147-163, 1997.

19. Kaya Y, Cebi A, Soylemez N, Demir H, Alp HH, and Bakan E. Correlations between oxidative DNA damage, oxidative stress and coenzyme Q10 in patients with coronary artery disease. Int J Med Sci 9: 621-626, 2012.

20. Keaney JF, Jr., Larson MG, Vasan RS, Wilson PW, Lipinska I, Corey D, Massaro JM, Sutherland P, Vita JA, and Benjamin EJ. Obesity and systemic oxidative stress: clinical correlates of oxidative stress in the Framingham Study. Arterioscler Thromb Vasc Biol 23: 434-439, 2003.

21. Kim JY, Lee JW, Youn YJ, Ahn MS, Ahn SG, Yoo BS, Lee $\mathrm{SH}$, Yoon $\mathrm{J}$, and Choe $\mathrm{KH}$. Urinary levels of 8-iso- 
prostaglandin f2alpha and 8-hydroxydeoxyguanine as markers of oxidative stress in patients with coronary artery disease. Korean Circ J 42: 614-617, 2012.

22. Kroese LJ and Scheffer PG. 8-Hydroxy-2'-deoxyguanosine and cardiovascular disease: a systematic review. Curr Atheroscler Rep 16: 452, 2014.

23. Lai CQ, Tucker KL, Parnell LD, Adiconis X, Garcia-Bailo B, Griffith J, Meydani M, and Ordovas JM. PPARGC1A variation associated with DNA damage, diabetes, and cardiovascular diseases: the Boston Puerto Rican Health Study. Diabetes 57: 809-816, 2008.

24. Lin HJ, Chen ST, Wu HY, Hsu HC, Chen MF, Lee YT, Wu $\mathrm{KY}$, and Chien KL. Urinary biomarkers of oxidative and nitrosative stress and the risk for incident stroke: a nested case-control study from a community-based cohort. Int $J$ Cardiol 183: 214-220, 2015.

25. Loffredo L, Pignatelli P, Cangemi R, Andreozzi P, Panico MA, Meloni V, and Violi F. Imbalance between nitric oxide generation and oxidative stress in patients with peripheral arterial disease: effect of an antioxidant treatment J Vasc Surg 44: 525-530, 2006.

26. Mendes B, Silva P, Mendonca I, Pereira J, and Camara JS. A new and fast methodology to assess oxidative damage in cardiovascular diseases risk development through eVolMEPS-UHPLC analysis of four urinary biomarkers. Talanta 116: 164-172, 2013.

27. Moher D, Liberati A, Tetzlaff J, and Altman DG. Preferred reporting items for systematic reviews and meta-analyses: the PRISMA statement. PLoS Med 6: e1000097, 2009.

28. Nagayoshi Y, Kawano H, Hokamaki J, Miyamoto S, Kojima S, Shimomura H, Tsujita K, Sakamoto T, Yoshimura $M$, and Ogawa H. Urinary 8-hydroxy-2'-deoxyguanosine levels increase after reperfusion in acute myocardial infarction and may predict subsequent cardiac events. Am J Cardiol 95: 514-517, 2005.

29. Nagayoshi Y, Kawano H, Hokamaki J, Uemura T, Soejima H, Kaikita K, Sugiyama S, Yamabe H, Shioji I, Sasaki S, Kuroda Y, and Ogawa H. Differences in oxidative stress markers based on the aetiology of heart failure: comparison of oxidative stress in patients with and without coronary artery disease. Free Radic Res 43: 1159-1166, 2009.

30. Najar RA, Ghaderian SMH, Vakili H, Panah AST, Farimani AR, Rezaie G, and Harchegani AB. The role of p53, bax, bcl2, and $8-\mathrm{OHdG}$ in human acute myocardial infarction. Cent Eur J Biol 5: 439-445, 2010.

31. Redon J, Oliva MR, Tormos C, Giner V, Chaves J, Iradi A, and Saez GT. Antioxidant activities and oxidative stress byproducts in human hypertension. Hypertension 41: 10961101, 2003.

32. Romer W, Oettel M, Menzenbach B, Droescher P, and Schwarz S. Novel estrogens and their radical scavenging effects, iron-chelating, and total antioxidative activities: 17 alpha-substituted analogs of delta 9(11)-dehydro-17 betaestradiol. Steroids 62: 688-694, 1997.

33. Rosello-Lleti E, de Burgos FG, Morillas P, Cortes R, Martinez-Dolz L, Almenar L, Grigorian L, Orosa P, Portoles M, Bertomeu V, and Rivera M. Impact of cardiovascular risk factors and inflammatory status on urinary 8-OHdG in essential hypertension. Am $J$ Hypertens 25: 236-242, 2012.

34. Ross R. Atherosclerosis - an inflammatory disease. $N$ Engl J Med 340: 115-126, 1999.

35. Rozalski R, Migdalski A, Gackowski D, Guz J, Siomek A, Foksinski M, Szpila A, Zarakowska E, Majer M, Jawien A, and Olinski R. Does morphology of carotid plaque depend on patient's oxidative stress? Clin Biochem 46: 1030-1035, 2013.

36. Serdar M, Sertoglu E, Uyanik M, Tapan S, Akin K, Bilgi C, and Kurt I. Comparison of 8-hydroxy-2'-deoxyguanosine (8-OHdG) levels using mass spectrometer and urine albumin creatinine ratio as a predictor of development of diabetic nephropathy. Free Radic Res 46: 1291-1295, 2012.

37. Shi GX, Liu CZ, Wang LP, Guan LP, and Li SQ. Biomarkers of oxidative stress in vascular dementia patients. Can J Neurol Sci 39: 65-68, 2012.

38. Shigenaga MK, Gimeno CJ, and Ames BN. Urinary 8hydroxy-2'-deoxyguanosine as a biological marker of in vivo oxidative DNA damage. Proc Natl Acad Sci U S A 86: 9697-9701, 1989.

39. Sies H. Oxidative stress: from basic research to clinical application. Am J Med 91: 31S-38S, 1991.

40. Simic MG. Urinary biomarkers and the rate of DNA damage in carcinogenesis and anticarcinogenesis. Mutat Res 267: 277-290, 1992.

41. Sterne JA, Egger M, and Smith GD. Systematic reviews in health care: investigating and dealing with publication and other biases in meta-analysis. BMJ 323: 101-105, 2001.

42. Tang $M$ and Subbiah MT. Estrogens protect against hydrogen peroxide and arachidonic acid induced DNA damage. Biochim Biophys Acta 1299: 155-159, 1996.

43. Topic A, Francuski D, Markovic B, Stankovic M, Dobrivojevic S, Drca S, and Radojkovic D. Gender-related reference intervals of urinary 8-oxo-7,8-dihydro-2'deoxyguanosine determined by liquid chromatographytandem mass spectrometry in Serbian population. Clin Biochem 46: 321-326, 2013.

44. Valko M, Leibfritz D, Moncol J, Cronin MT, Mazur M, and Telser J. Free radicals and antioxidants in normal physiological functions and human disease. Int $J$ Biochem Cell Biol 39: 44-84, 2007.

45. Wang Y, Yu Q, Chen Y, and Cao F. Pathophysiology and therapeutics of cardiovascular disease in metabolic syndrome. Curr Pharm Des 19: 4799-4805, 2013.

46. Xiang F, Shuanglun X, Jingfeng W, Ruqiong N, Yuan Z, Yongqing L, and Jun Z. Association of serum 8-hydroxy2 -deoxyguanosine levels with the presence and severity of coronary artery disease. Coron Artery Dis 22: 223-227, 2011.

47. Yin B, Whyatt RM, Perera FP, Randall MC, Cooper TB, and Santella RM. Determination of 8-hydroxydeoxyguanosine by an immunoaffinity chromatography-monoclonal antibody-based ELISA. Free Radic Biol Med 18: 10231032, 1995.

Address correspondence to:

Dr. Alessandro Di Minno

Centro Cardiologico Monzino

IRCCS

Via C. Parea 4

20138 Milan

Italy

E-mail: alessandro.diminno@ccfm.it

Date of first submission to ARS Central, September 23, 2015; date of final revised submission, November 16, 2015; date of acceptance, December 3, 2015. 


$\begin{aligned} & \text { Abbreviations Used } \\ & \text { 8-OHdG }=8 \text {-hydroxy-2-deoxyguanosine } \\ & 95 \% \mathrm{CI}=95 \% \text { confidence interval } \\ & \mathrm{BMI}=\text { body-mass index } \\ & \mathrm{CAD}=\text { coronary artery disease } \\ & \mathrm{CVD}=\text { cardiovascular disease } \\ & \mathrm{ELISA}=\text { enzyme-linked immunosorbent assay }\end{aligned}$

$\begin{aligned} & \mathrm{MD}= \text { mean difference } \\ & \mathrm{MS}= \text { mass spectrometry } \\ & \text { PRISMA }= \text { Preferred Reporting Items for } \\ & \text { Systematic reviews and } \\ & \text { Meta-Analyses } \\ & \mathrm{ROS}=\text { reactive oxygen species } \\ & \mathrm{SMD}=\text { standard mean difference }\end{aligned}$

